Article

\title{
Basic Chemical Tests of Concrete during the Assessment of Structure Suitability-Discussion on Selected Industrial Structures
}

\author{
Jacek Hulimka and Marta Kałuża *(1) \\ Faculty of Civil Engineering, Silesian University of Technology, 44-100 Gliwice, Poland; jacek.hulimka@polsl.pl \\ * Correspondence: marta.kaluza@polsl.pl; Tel.: +48-32-237-20-37
}

Received: 12 November 2019; Accepted: 28 December 2019; Published: 3 January 2020

\begin{abstract}
Making a decision to perform an overhaul of a damaged reinforced concrete structure should be preceded by an analysis of the real durability of that structure after the repair in connection with the anticipated service life. One of the basic problems is the avoidance of further corrosion of concrete and steel after the repair, which depends on the degree of concrete contamination with harmful chemical factors. It is particularly important to determine the content of chloride and sulfate ions which cause corrosion. Concrete $\mathrm{pH}$ is equally significant because it conditions effective passivation of the reinforcement. The paper presents the basic issues related to the main chemical threats, including the main sources of their origin as well as their limit values. It emphasizes the importance of conducting the chemical tests of concrete, which should be treated as one of the methods of determining structure suitability for an overhaul, especially in the context of subsequent durability. This seems obvious to an experienced specialist, but in practice, such studies are often ignored. Those considerations are backed up with selected examples of reinforced concrete industrial structures exposed to aggressive chemicals during their operation. The text shows the correlation between their technical condition and chemical test results as well as the influence of those results on making decisions concerning effective overhauls.
\end{abstract}

Keywords: reinforced concrete; durability; chemical tests; diagnostic; industrial structures; corrosion

\section{Introduction}

Given the present development of construction chemistry, the thesis that nearly every reinforced concrete (RC) structure can be repaired even if its technical condition is very bad can be proposed. By technical condition, the authors understand the actual condition of the RC element, taking into account its original manufacturing defects, mechanical damage, and chemical pollution-in relation to a new, properly made element. A repair is defined herein as restoration of original features of the structure, especially its load-bearing capacity and rigidity. The proposed thesis is true to a certain extent, but it requires answering the following questions.

- Is the repair cost-effective from an economic point of view?

- Does the scope of the necessary repair works actually cover the replacement of substantial parts of the structure (which would be reconstruction or modernization rather than a repair)?

- What will the real structure durability be after the repair and is it satisfactory concerning the anticipated further service life of the facility?

Certainly, the above questions do not cover all the doubts. This paper discusses the real durability of repaired RC structures from which a relatively long period of further service life is required. 
Examples presented in the paper include RC support structures of power boilers and trestle bridges under industrial systems. In those cases, industrial devices are fairly often replaced entirely-this raises a question concerning the possibility of performing an overhaul of the RC support structure and using it further. This is caused both by the willingness to save money and the time pressure related to the performed works. However, the economic aspect is usually less important because repairing a severely damaged structure is quite costly as well-which results from the cost analysis of repairs of real objects that the authors performed during their many years of practice in evaluating and planning various overhauls of RC structures. The willingness to save time is more significant-demolition and reconstruction of an RC structure last much longer than its repair. Therefore, an investor relatively often forces a repair of RC support structures even if their technical condition is very bad.

Both object owners, as well as designers dealing with such repairs, often think that appropriately applied repair materials allow restoring the original features of a damaged structure. In principle, such a stance is justified if one takes into account a period lasting a few years. However, the service life of new power boilers, process pipelines, and other industrial devices is defined as 20-30 years and sometimes even more. Thus, the use of support structures should be planned for the same period. This creates a problem of assessing the suitability of a damaged structure for repairs guaranteeing reliable operation throughout an anticipated long period. From a practical point of view, it is important that the assessment method should be relatively quick and cheap and does not require specialized equipment or examination techniques.

This study investigated the influence of basic concrete chemical tests on RC structure suitability for an overhaul through literature review and case-studies verification. The basic threats to RC structure durability, with particular reference to chemical factors, are presented and discussed. This stems from the fact that any mechanical damage can be repaired because its causes are usually temporary-as an example, damage to the hall's supporting column as a result of being hit by a forklift [1]. On the other hand, chemical agents usually cause permanent changes that hinder durable repairs or reinforcements and sometimes even make those impossible-as shown in this paper. The main thesis of this paper that the factor determining the possibility of effective and durable repairs of a corroded RC structure is its chemical condition is discussed and confirmed by actual cases of damaged industrial structures.

\section{Basic Threats to RC Structure Durability-Short Literature Review}

Reinforced concrete is a durable structural material and the steel reinforcement inside it is safe from corrosion. The above is true under the condition that the concrete and the reinforcing steel is well-protected against corrosion beforehand. In the case of relatively new concrete with correct composition and structure (high $\mathrm{pH}$ ), the reinforcing steel surface is passivated and effectively protected against corrosion [2]. However, concrete surface $\mathrm{pH}$ decreases in time, which makes the concrete gradually lose its protective properties. Simultaneously, the threat of concrete contamination with aggressive chemical agents increases as they penetrate the concrete near the reinforcement. Concrete contamination is both aggressive ions (chloride, sulfate, nitrogen) from the environment, as well as carbon dioxide causing carbonation. If a structure is continuously exposed to aggressive chemical factors, this process becomes progressive. Corrosion processes can be significantly delayed by using various types of concrete surface protection against the penetration of aggressive factors [3-5] or the use of low absorption concrete [6].

Very simplified divisions group factors threatening RC structure durability into mechanical, atmospheric, biological, and chemical ones [7]. In practice, it is sometimes hard to distinguish between separate risk factors because their effects are often strongly interrelated (e.g., chemical aggression causes steel corrosion; then, swelling corrosion products burst concrete, which is a mechanical action). The selected examples presented below are aimed at depicting their influence on the possibility of a durable and effective structure repair.

Purely mechanical damage often results from impact or other action which are incidental [1]. In such cases, the usefulness of the damaged element for repair must be determined by the size of 
the damage and the cost-effectiveness of the repair in relation to the costs of replacing a part of the structure. Another type of mechanical damage is concrete surface abrasion by a stream of liquid or gas-this does not influence structure suitability for an overhaul, either. A specific group is mechanical damage resulting from repeated repetitive fatigue loads. Reinforced concrete crane beams are a good example here. In this case, the occurrence of mechanical damage usually prevents effective repairs, because the structure of concrete and reinforcing steel is damaged.

Most cases of atmospheric damage have the form of frost corrosion. Therefore, those do not preclude durable repairs, even though they do result in cover thinning, thus facilitating chemical aggression.

Many biological factors also come down to mechanical action, for example when plant roots burst concrete. Sometimes the organisms living on the concrete surface are chemically aggressive as well. For example, lichens can cause chemical decomposition of concrete and pollute it with sulfur compounds. The activity of bacteria is equally detrimental as they can also pollute concrete with sulfur compounds [8-10].

Still, chemical agents form the most significant group of impact factors causing corrosion of concrete and reinforcement. Some of them are present in the atmosphere-an example is carbon dioxide which causes carbonation in concrete $[7,11]$. Other typical corrosion factors are sulfur compounds, which form gypsum in concrete (through the reaction of sulfate ions with portlandite) and, in the subsequent phase, ettringite which can be, or not, expansive. Sulfur compounds are present, among other things, in the so-called industrial atmosphere and in a part of groundwater [7,12]. The abovementioned biological corrosion is also a source of concrete contamination with sulfur compounds. Publication [13] contains an interesting overview covering the territory of Germany. The authors undermine, to a certain extent, the classical idea of a sulfate attack caused by the migration of sulfate ions from soil or water and highlight the detrimental influence of gypsum.

Another widespread corrosion agent is sodium chloride, found naturally in seawater and a part of the groundwater. Its significant concentrations are also transferred to the environment during the deicing of communication surfaces. Chlorides react with cement hydration products (calcium hydroxide i.e., portlandite, C-S-H phase), destroy the passivation layer and directly cause steel corrosion $[12,14,15]$. A specific source of chlorides is also coal mine water, a huge volume of which is discharged to surface waters. In the years 1995-1998, the daily discharge of $\mathrm{Cl}^{-}$and $\mathrm{SO}_{4}{ }^{2-}$ salts to the upper drainage basin of the Odra and Vistula Rivers was approximately 7000 tons [16]. For example, water from the level of $665 \mathrm{~m}$ in the "Wesoła" coal mine contains more than $35 \mathrm{~g} / \mathrm{dm}^{3}$ of chloride ions [17]; in extreme cases, that content reaches $200 \mathrm{~g} / \mathrm{dm}^{3}$ [16]. That water often comes into contact with industrial structures, introducing chloride ions into the concrete. Such a situation was described in the paper [18] where, among others, the corrosion of the RC silo caused by coal mine water led to extensive structural failure.

Certain effects of chemical aggression also exert a mechanical impact. This happens in three ways:

- New chemical compounds forming in concrete increase their volume and burst the surrounding material (ettringite, gypsum, thaumazite, Candlot salt, calcium carbonate, expansive calcium chloride, and expansive magnesium chloride);

- Similarly, swelling products of reinforcing steel corrosion burst the concrete cover (ion oxides and hydroxides);

- Soluble compounds forming in concrete discharge a portion of the matter beyond the concrete element (acid calcium carbonate).

The abovementioned factors are not an exhaustive list of the enormous number of chemical substances aggressive for concrete, but they are the most common and relatively easy to examine ones. The latter part of the paper describes the results of basic laboratory tests concerning the assessment of concrete pollution with the typical chemical factors as well as relates the obtained results to the possibility and justifiability of industrial support structure repairs. 
Due to the nature of the paper, a chemical description of corrosive processes is not included herein because the content and aim of the paper are different. Such descriptions can be found in a number of references [7,19-21].

The article also omits issues related to the use of typical non-destructive tests [22] and non-destructive electrochemical techniques to evaluate the corrosion of steel reinforcement-including the examination of the corrosion potential of steel and the corrosion rate of steel [23-25]. Such tests are extremely helpful in assessing the risk of steel corrosion in RC; however, their main advantage is determining the level of steel corrosion without disturbing the continuity of concrete cover. Meanwhile, the article describes the cases of constructions in which the degree of corrosion damage was so significant that the use of advanced non-destructive methods was unnecessary-most of the corrosion damage was clearly visible.

\section{Chemical Tests}

\subsection{Need for Chemical Tests}

An analysis of numerous technical studies concerning repairs of RC structures after many years of operation shows that the most frequently recommended works are those consisting in the removal of visible damage to concrete and reinforcement. Therefore, the recommendations come down to a number of activities which, assuming a certain simplification, can be described as follows: Hacking off damaged or weakened concrete, cleaning the surface of concrete and the uncovered reinforcement, supplementation of significant reinforcement losses, application of a bonding layer (in some systems preceded by application of corrosion inhibitors on rebars), filling of deep losses, filling of shallow losses (patching), and (not always) application of protective layers. Typical polymer cement concrete (PCC) repair systems are usually recommended here.

The range and scope of necessary repairs with the relevant requirements have been described in detail in a group of Polish standards PN-EN 1504-Products and systems for the protection and repair of concrete structures (part 1 to 10) [26].

Such an approach leads to the restoration of the original geometry of the element (and restoration of reinforcement, if necessary). However, the success may be ostensible if the original concrete in structure is strongly carbonated or contaminated with harmful ions retained in the deeper layers. In such a case, the original concrete and the reinforcement are exposed to corrosion which starts virtually right after repair completion. The application of appropriate corrosion inhibitors does slowdown that process, but it progresses much faster than in new concrete anyway.

One must also remember that supplementing the corroded reinforcement so that the original amount is restored, which is often done in practice, may prove insufficient. First, the deformations of the original and new reinforcement are not compatible. Second, the yield strength of corroded rebars is lowered [27]. The latter aspect is also related to chemical contamination of concrete and the possibility of a durable repair of the structure.

Meanwhile, there is a simple and cheap method of determining the potential effectiveness of RC repairs throughout a longer period. In each case, one should conduct at least random examinations of the basic chemical features of the original concrete, including $\mathrm{pH}$ and the content of chloride and sulfate ions. Depending on the obtained results, the structure may:

- Be repaired without additional treatment;

- Undergo additional treatment (e.g., re-alkalization or electrochemical chloride extraction ECE) if the results point to a corrosion threat, but the condition of concrete can be improved;

- Not be qualified for repair due to a significant threat to durability.

Unfortunately, the last option is rarely applied in practice. Examples of the effects of such conduct shall be shown in the next chapter.

The authors argue that in the case of every RC structure used for a long period or in conditions threatening it with concrete penetration by chlorine or sulfur compounds, the decision to repair the 
corrosive damage should be determined by conducting basic chemical examinations of concrete. Those examinations are relatively cheap and do not take much time. Their results, if interpreted correctly, allow one to make an informed decision about repairing the RC structure with its durability in mind.

\subsection{Typical Methods of Chemical Testing}

\subsubsection{Determination of the Chloride and Sulfate Ions}

Generally, chloride and sulfate ions content tests should be carried out on powdered samples of concrete taken during drilling or from core drilling or other concrete fragments obtained from the structure. Test samples should be taken from representative places (in concrete cover, especially at the reinforcement surface) where there is a risk of pollution. It is recommended that samples be taken from different depths. The minimum required amount of sample is $1 \mathrm{~g}$, however, when collecting powdered samples it is recommended to collect about $20 \mathrm{~g}$ of the material, so as to ensure the representativeness of all concrete components. The test drilling should have a diameter of 30 to $50 \mathrm{~mm}$; they can be cut into slices or crushed at different depths.

There are two similar chemical laboratory tests that allow direct determination of chloride content in a concrete sample (mass percentage of chloride referred to total concrete or to binder) - the Mohr or Fajans method [28,29]. In both cases, the principle of the method is the reaction of precipitation from a solution containing $\mathrm{Cl}^{-}$ions (concrete power) of sediment $(\mathrm{AgCl})$ using a silver nitrate solution $\left(\mathrm{AgNO}_{3}\right)$ of an exactly known concentration. In the first method, potassium chromate $\left(\mathrm{K}_{2} \mathrm{CrO}_{4}\right)$ is used as an indicator, which causes the solution to become reddish-brown. The test environment must be neutral or weakly alkaline ( $\mathrm{pH}$ from 7 to 10.5). In the case of the Fajans method, a different indicator is used. This is fluorescein in the form of an aqueous solution of fluorescein sodium, which is an adsorption indicator. This causes color changes that are observed, not in the solution (as in the Mohr method), but on the surface of the sediment. In this method, the chlorides can only be determined in neutral solutions. To calculate the chloride content, an equation is used that is identical in both methods.

There is also a standard way of determining the chloride content in hardened concrete described in the PN-EN 14629:2008-Products and systems for the protection and repair of concrete structures; Test methods-determination of chloride content in hardened concrete [30]. The procedure for the determination of chloride ions by the Volhard method (Method A) and the potentiometric method (Method B) are described here. Method A is quite similar to the described above two (Mohr or Fajans) with a different type of indicator. This is an iron-ammonium alum, which forms a red complex with the first drop of excess thiocyanate solution. Method B is based on potentiometric titration [31] of a silver nitrate solution $\left(\mathrm{AgNO}_{3}\right)$. The test consists of adding small multiples of the solution to the powered concrete sample, recording potential changes, and determining the first derivatives from the obtained data. In both cases (Methods A and B), the standard provides a formula for calculating the chloride content as a percentage of chloride ions in relation to the sample mass. The Volhard method is the most commonly used in practice for the determination of the chloride content in concrete [32]. The main Rilem recommendations are based on this method [33,34].

To determine the content of sulfate ions in the concrete sample, a typical chemical laboratory test - the gravimetric method [28]—is used. The determination is based on the precipitation of sulfates from the concrete power (on hot) in acidic solution $(\mathrm{HCl})$, using barium chloride $\left(\mathrm{BaCl}_{2}\right)$. Then, the hardly soluble barium sulfate $\left(\mathrm{BaSO}_{4}\right)$ is precipitated, which after roasting is weighed and converted into the content of $\mathrm{SO}_{4}{ }^{2-}$ ions.

\subsubsection{Carbonation-Determination of the $\mathrm{pH}$ Value}

There are two typical methods to determine the $\mathrm{pH}$ value of hardened concrete. The first one is the laboratory method and the second one uses the indicator, which is sprayed onto the surface of the concrete breakthrough. 
The first method is very precise and is made using a $\mathrm{pH}$-meter. The $\mathrm{pH}$ value is measured in water extracts obtained after the treatment of the crushed concrete sample with boiling water. The weight ratio here is 1 part concrete to 10 parts water. In this method, it is important to separately test samples from individual layers (depths) of concrete, because a test made of a too deep part of the concrete cover gives an average result.

The indicator methods are simplified, which can be used also as in-situ tests. They consist of spraying on the fresh concrete breakthrough the appropriate indicator preparation and reading the $\mathrm{pH}$ value from the available range. The following types of tests can be used.

- Phenolphthalein or thymolphthalein test.

The first one complies with the PN-EN 14630:2007 standard [35]. The indicator here is an alcohol solution of phenolphthalein, which is colored on red-purple only at $\mathrm{pH}$ values higher than $8.5 \div$ 9.5. This is quite a rough estimate of the $\mathrm{pH}$ value. A more accurate estimate can be obtained by using the second test, where the indicator is thymolphthalein. The concrete surface is colored in navy blue, at $\mathrm{pH}$ values higher than $\mathrm{pH} 9.3 \div 10.5$

- Rainbow test.

This test is the most accurate of the indicator tests available [22]. It allows the assessment of the intensity of the carbonation process, due to the dyeing of the concrete breakthrough in various colors in the range from $\mathrm{pH} 5$ to $\mathrm{pH} 13$.

Figure 1 shows the colors obtained for the appropriate $\mathrm{pH}$ value at the above indicator tests. The color, and thus the $\mathrm{pH}$ value, also identifies the level of carbonation.

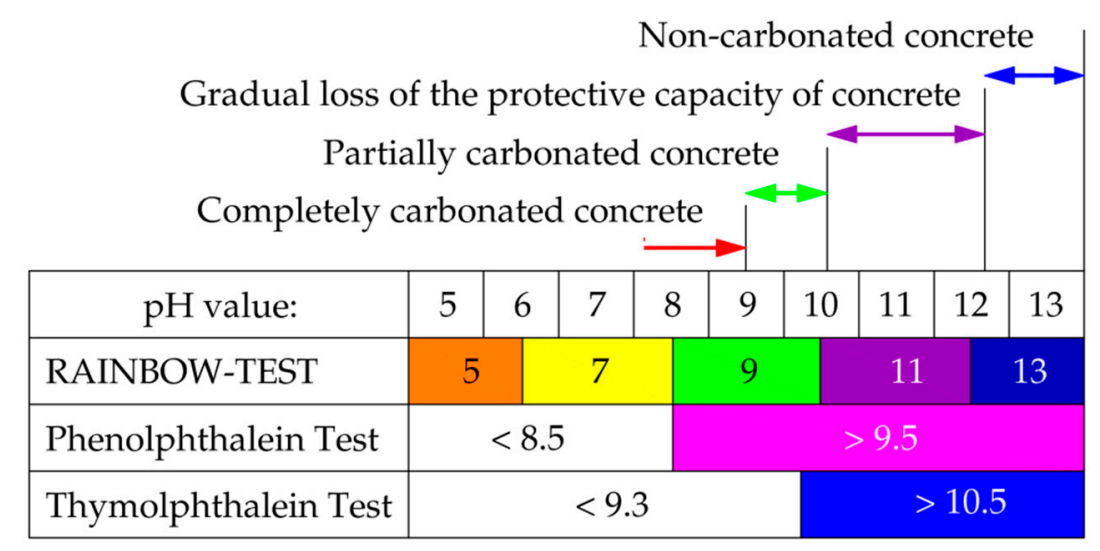

Figure 1. The colors used to determine the $\mathrm{pH}$ value of concrete and its carbonation level.

\subsection{Permissible Values of Tested Parameters}

The recommendations contained in the European standards and the model standard, fib-Model Code 2010, concerning concrete durability in relation to corrosion factors are described in detail in [21] and other publications. In general, the design of an overhaul or modernization of an RC structure has to be based on the recommendations contained in the standards (in the scope of the permissible content of harmful ions) and utilize generally accepted, examination-based $\mathrm{pH}$ values.

The conducted chemical examinations focused on three basic parameters: The content of chloride ions $\left(\mathrm{Cl}^{-}\right)$and of sulfate ions $\left(\mathrm{SO}_{4}{ }^{2-}\right)$, as well as the concrete reaction connected to the carbonation process.

Under PN-EN 206+A1. Concrete-Specification, performance, production and conformity [36], the maximal content of chloride ions $\left(\mathrm{Cl}^{-}\right)$in concrete in relation to the cement mass (including type II additives) is: $0.1 \%$ or $0.2 \%$ in structures with prestressing steel reinforcement; $0.2 \%$ or $0.4 \%$ in structures with ordinary steel reinforcement; $1.0 \%$ in structures without reinforcement. Such strict requirements (as well as their differentiation depending on the presence and type of reinforcement) 
stem from the fact that chloride ions do not only cause concrete corrosion, but also-or actually first and foremost-corrosion of steel reinforcement and other elements $[7,14]$. Determination of chloride content in relation to cement is convenient because it allows obtaining reproducible results and presents the proportions between the aggressive action of chlorides and the inhibiting effect of cement [37]. At the same time, the literature contains a number of author's concepts concerning critical chloride content as well as chloride content examination methods [38-40]; unfortunately, some of them lead to certain interpretation contradictions, thus hindering assessment of results. It should be highlighted that under PN-EN 197-1:2012 standard [41] chloride content in cement as the construction material must not exceed $0.1 \%$.

The maximal content of sulfate ions $\left(\mathrm{SO}_{4}{ }^{2-}\right)$ is $0.5 \%$ of the concrete mass. Given the cement content of $300 \mathrm{~kg} / \mathrm{m}^{3}$ of concrete mixture, this means approx. $3 \%$ in relation to binder mass. This value is relatively high, but one must be aware that a certain amount of sulfur compounds is already contained in cement and their excessive amount that penetrates the material comes from the surroundings of the structure.

The concrete reaction is not regulated by provisions of standards, but numerous tests conducted allow to state certain universal recommendations. In the first phase of material existence, the reaction is strongly basic - $\mathrm{a} \mathrm{pH}$ of more than 12 . The reaction of carbon dioxide with calcium hydroxide creates calcium carbonate, which initially has a good influence on the structure because it seals the structure surface [11]. At the next stage, calcium carbonate is transformed into soluble bicarbonate ions which are then washed out from the structure. This process lowers concrete reaction and deteriorates concrete structure. It is a progressive phenomenon, both in terms of concrete reaction lowering in a given layer and the depth at which it takes place. If concrete $\mathrm{pH}$ is lowered to approx. 11.8, the passivation layer on the reinforcement is damaged for the first time, which initiates corrosion processes. Further $\mathrm{pH}$ decrease results in the complete destruction of the passivation layer and a risk of serious corrosive damage to the reinforcement. Long-lasting carbonation may lower concrete $\mathrm{pH}$ even to 8.3 [42], causing the anti-corrosive properties of the cover to disappear completely.

\section{Discussion Based on Practical Examples}

\subsection{A Short Description of the Structures}

To back up the above descriptions with practical examples, the paper cites the results of the basic chemical tests of concrete in selected industrial support structures. The cited results are compared with the actual technical condition of the structures in question.

All the structures were built in the second half of the 20th century and their age (and operation period) at the time of the examinations was $45-55$ years.

The first case was a support structure of a WR- 25 power boiler. The structure consisted of a bottom slab (on piles) and a spatial frame resting on it. The frame consisted of nine columns and a top grid tied with a plate with openings. This structure is hereinafter referred to as A.

In the second case, the analysis covered the support structures of four power boilers-three of the WLM- 5 type and one of the WR-10 type. Each of the identical support structures of WLM- 5 boilers consisted of a bottom slab with two flat frames fixed in it. Each frame consisted of two columns joined by a lock with brackets and the locks were joined by a plate. Those structures are hereinafter referred to as B1, B2, and B3. The support structure of the WR-10 boiler was similar, but each frame contained three columns. This one is hereinafter referred to as B4.

In the third case, the analysis covered two identical foundations of WLM-25 boilers which were geometrically similar to the first foundation (A), but their dimensions were different. Those structures are hereinafter referred to as $\mathrm{C} 1$ and $\mathrm{C} 2$.

The fourth case was slightly different in terms of construction because it was a pipeline support system in a steel plant. The trestle bridge was designed and built as an RC one, structurally joined with an open water channel. In structural terms, the trestle was an RC spatial frame consisting of two-level 
columns joined by longitudinal and transverse locks; the top tier beams were joined by a plate. At an unknown time, the top longitudinal beams were confined in a steel sheet housing. In the past, the columns were additionally concreted and confined in steel elements; those reinforcements did not reach the foundation level. Most of the structural elements bore traces of past repairs made using PCC materials. The structure is marked as D.

All the presented facilities are RC monolithic structures operated in industrial conditions, including exposure to process water. All those structures can also be divided into an underground part and a part above the ground. This division is very important here because it distinguishes between two zones characterized by varying exposure to the external corrosive impact.

\subsection{Structural Materials}

To determine concrete strength, core samples were tested. That was supplemented with a sclerometric test and the correlation coefficient was determined each time. The obtained results are presented in Table 1, including the class to which the concrete corresponds. The design values obtained from the original design documentation (wherever available) are in the original units.

Table 1. Concrete classes—designed and applied (tested).

\begin{tabular}{cccccc}
\hline \multirow{2}{*}{ Structure } & Designed Concrete & \multicolumn{3}{c}{ Actual Concrete (Tested) } \\
\cline { 3 - 6 } & & Foundation & Columns & Beams & Slabs \\
\hline A & $\mathrm{R}_{\mathrm{W}}=170 \mathrm{kG} / \mathrm{cm}^{2}$ & - & $\mathrm{C} 16 / 20$ & $\mathrm{C} 16 / 20$ & - \\
$\mathrm{B} 1-\mathrm{B} 3$ & $\mathrm{R}_{\mathrm{W}}=170 \mathrm{kG} / \mathrm{cm}^{2}$ & - & $\mathrm{C} 12 / 15$ & $\mathrm{C} 12 / 15$ & - \\
$\mathrm{B} 4$ & $\mathrm{R}_{\mathrm{W}}=170 \mathrm{kG} / \mathrm{cm}^{2}$ & - & $\mathrm{C} 12 / 15$ & $\mathrm{C} 12 / 15$ & - \\
$\mathrm{C} 1-\mathrm{C} 2$ & - & $\mathrm{C} 20 / 25$ & $\mathrm{C} 20 / 25$ & $\mathrm{C} 16 / 20$ & - \\
$\mathrm{D}$ & - & - & $\mathrm{C} 16 / 20$ & $\mathrm{C} 16 / 20$ & - \\
\hline
\end{tabular}

The steel grade was determined based on ribbing (Table 2). St0 was assumed for smooth steel. The access to the individual types of rebars was obtained by performing core drilling or uncovering or by utilizing the areas where the corrosion processes had already uncovered the rebar surface.

Table 2. Designed and applied (tested) reinforcing steel.

\begin{tabular}{ccccccccc}
\hline \multirow{2}{*}{ Structure } & \multicolumn{3}{c}{ Designed Steel } & \multicolumn{4}{c}{ Steel Found in the Uncovered Areas } \\
\cline { 2 - 9 } & Foundation & Columns & Beams & Slabs & Foundation & Columns & Beams & Slabs \\
\hline A & $18 G 2 / S t 0$ & $18 G 2 / S t 0$ & $18 G 2 / S t 0$ & St0 & - & $18 G 2 / S t 0$ & $18 G 2 / S t 0$ & St0 \\
B1-B3 & St0 & St0 & St0 & St0 & St0 & $34 G S / S t 0$ & $34 G S / S t 0$ & St0 \\
B4 & - & - & - & - & - & $34 G S / S t 0$ & $34 G S / S t 0$ & $34 G S$ \\
C1-C2 & - & - & - & - & $34 G S / S t 0$ & $34 G S / S t 0$ & $34 G S / S t 0$ & St0 \\
D & - & - & - & - & - & St0 & St0 & St0 \\
\hline
\end{tabular}

\subsection{Results of Chemical Tests}

Concrete samples were collected for examinations from each of the structures. Some samples came from core drills, while others were collected independently by hacking off a cover fragment. The obtained examination results are presented in Table 3. In the case of a greater number of examinations, extreme values are presented. Each of the tests was done using a selected method described in Section 3.2.1. 
Table 3. Results of chemical tests.

\begin{tabular}{ccccc}
\hline \multirow{2}{*}{ Structure } & \multicolumn{5}{c}{ Chloride Ion Content ${ }^{*}[\%]$} \\
\cline { 2 - 5 } & Foundation & Columns & Beams & Slabs \\
\hline A & - & 3.4 & $1.1-4.3$ & 3.4 \\
B1-B3 & $0.2-0.7$ & $0.1-0.4$ & $0.1-0.5$ & $0.1-0.4$ \\
B4 & - & 0.3 & $0.2-0.5$ & 0.2 \\
C1-C2 & $0.1-0.4$ & $0.2-1.2$ & $0.2-2.1$ & $0.6-1.9$ \\
D & - & 2.9 & $3.3-7.5$ & 6.5 \\
\hline & \multicolumn{5}{c}{ Sulfate Ion Content * [\%] } \\
Structure & Foundation & Columns & Beams & Slabs \\
\cline { 2 - 5 } & - & 3.9 & $2.9-3.6$ & 0.9 \\
A & $3.4-3.9$ & $2.2-3.2$ & $1.7-4.0$ & $1.7-2.2$ \\
B1-B3 & - & 1.9 & $2.4-3.6$ & 3.3 \\
B4 & $2.2-2.9$ & $3.7-4.9$ & $4.4-8.9$ & $4.0-6.1$ \\
C1-C2 & - & 4.4 & $0.1-0.5$ & 1.8 \\
D & \multicolumn{5}{c}{ pH } \\
\hline & Foundation & Columns & Beams \\
Structure & - & 8.8 & $9.2-9.9$ & 10.1 \\
\cline { 2 - 5 } & F & $10.8-11.4$ & $10.6-11.2$ & 10.8 \\
A & $11.4-11.5$ & 10.4 & $10.2-11.4$ & 10.9 \\
B1-B3 & - & $10.0-10.8$ & $9.1-10.9$ & $8.8-10.6$ \\
B4 & $11.2-11.8$ & 8.3 & $10.1-11.0$ & 10.9 \\
C1-C2 & - & & & \\
D & & & & \\
\hline
\end{tabular}

* in relation to binder mass.

\subsection{Technical Condition of the Structures-Correlation with Chemical Examination Results}

The technical condition of all analyzed structures was defined independently for underground and above-ground elements. Three situations were identified—only after external inspections—-determining the intensity of observed damage. The technical condition was found as: satisfactory, bad, and very bad, which is summarized in Table 4.

Table 4. Results of identified technical condition.

\begin{tabular}{ccc}
\hline Structure & Underground Parts & Ground Parts \\
\hline A & - & very bad \\
B1-B3 & satisfactory & satisfactory \\
B4 & - & satisfactory \\
C1-C2 & satisfactory & bad/very bad \\
D & - & very bad \\
\hline
\end{tabular}

The total assessment of the technical condition, given in Table 4, was based on a number of factors. In terms of this article, the main determinant of technical condition should be the chemical condition of concrete associated with the risk of corrosion. However, the general condition of structure was also influenced by: Area of significant corrosion damage, the actual amount of reinforcement, conditions of use (both in the past and during the expected further operation), and the expected period of further use. Therefore, it is difficult to determine the unambiguous quantitative criteria for the classification of a structure to a given technical condition, because each time it was a combination of the factor described. The author's experience, which is difficult to quantify and based on many years of research and observations of similar structures played an important role in this identification of the technical condition. This, an attempt to quantify the condition of the structure, for example in the form of intervals of the number of points given in individual aspects and added up for the whole structure, can 
be very misleading because determining such a score and adopting appropriate weights will always be subjective.

During the inspections, corrosion intensity, damage of concrete (including mechanical ones), and different surface deposits were assessed and classified. In particular, the condition of structures observed was caused by corrosive damage to concrete (20-80\% of the surface of structural elements) as well as corrosion of reinforcing steel (from surface concrete to through practically the entire rebar) of varying intensity.

In general, a good correlation between the chemical test results and the structure technical condition was observed.

The best condition was demonstrated by all the elements from group B both in underground and above-ground parts. The corrosive damage to rebars was present only in the areas of original defects of the concrete cover which decreased its thickness (Figure 2a,b). The corrosion was visible mostly on the surface, with only small, isolated pitting spots. As shown in Table 3, the $\mathrm{pH}$ of all elements of those structures was at least 10.6 which indicates only a partial loss of the protective ability of concrete. Also, the content of chlorine and sulfate ions exceeded the permissible values only in certain areas. Interestingly, those foundations were made of concrete of the lowest class (C12/15), so it could be expected that their corrosion would be the highest. One of the reasons for the high ion concentration is the low density of concrete, which can be identified with its low class. However, the $\mathrm{pH}$ value was relatively high and pointed to only a small carbonation of the concrete. It is worth noting that the power boilers supported by group B structures were supplied with imported coal with a very low content of sulfur compounds and hardly any contact with mine water.

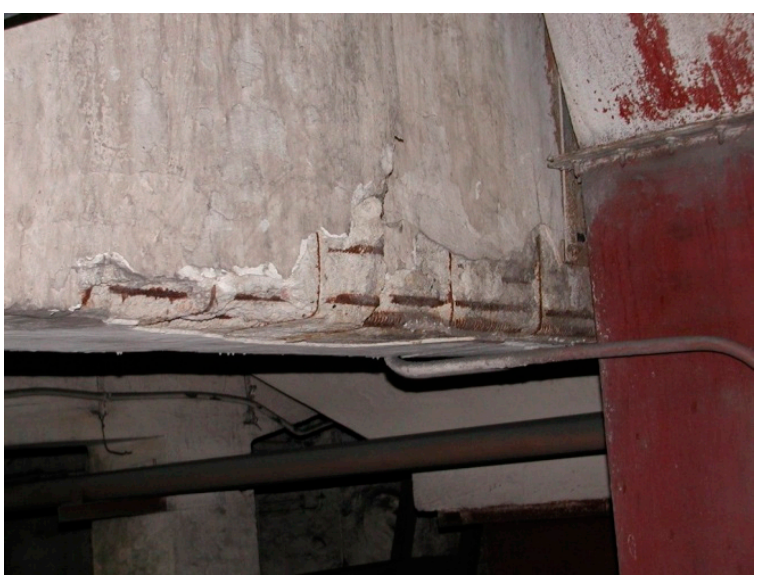

(a)

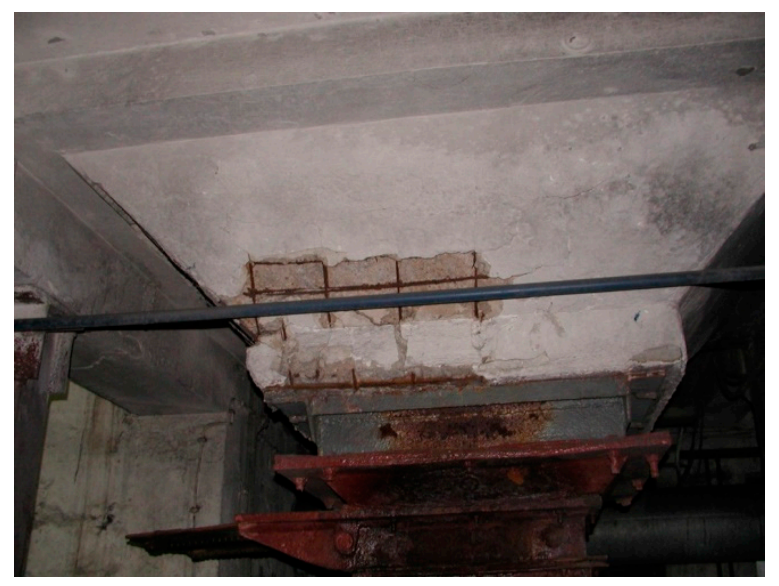

(b)

Figure 2. Examples of corrosive damage: $(\mathbf{a}, \mathbf{b})$ corrosion of steel rebars in defected concrete cover.

The test results for elements from structures $\mathrm{A}, \mathrm{C} 1$, and $\mathrm{C} 2$ were much worse. The $\mathrm{pH}$ value was as low as 10 or even less (except the foundation in structures $C$ ). The chloride ion content was enormous-it exceeded the permissible values several times. The worst situation was in all elements from structure A. The same applies to sulfate ion content. The permissible values in the parts of structures $\mathrm{C} 1$ and $\mathrm{C} 2$ above the ground were drastically exceeded. The underground parts of structures $\mathrm{C} 1$ and $\mathrm{C} 2$ were an exception because their $\mathrm{pH}$ exceeded 11 and the content of chloride and sulfate ions fell within the permissible range. The above was caused by tight flooring which did not let harmful agents come into contact with the concrete surface. The technical condition of the facilities determined on the basis of a visual assessment of the structures (Table 4) perfectly corresponds to the abovementioned test results-all the elements above the ground showed extensive corrosive damage to concrete and rebars; corrosion reduced the original cross-section of some rebars by as much as $50 \%$ or more (Figure $3 \mathrm{a}, \mathrm{b}$ and Figure $4 \mathrm{a}, \mathrm{b}$ ). 


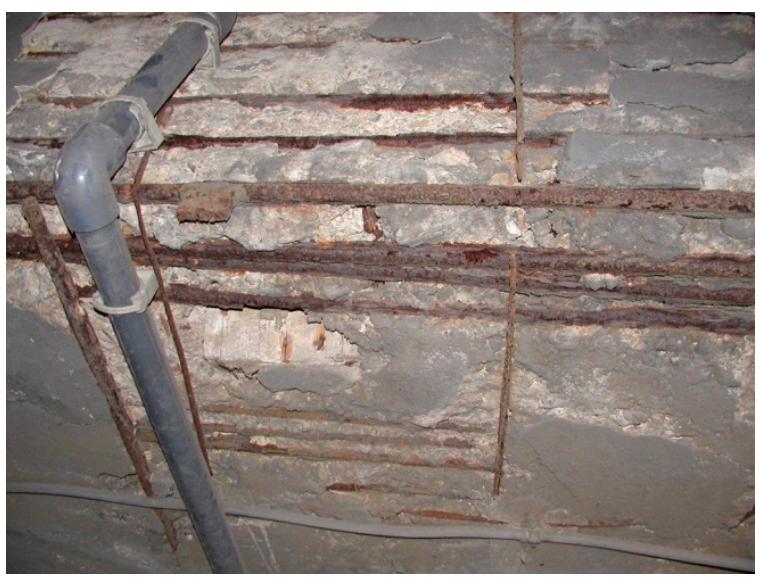

(a)

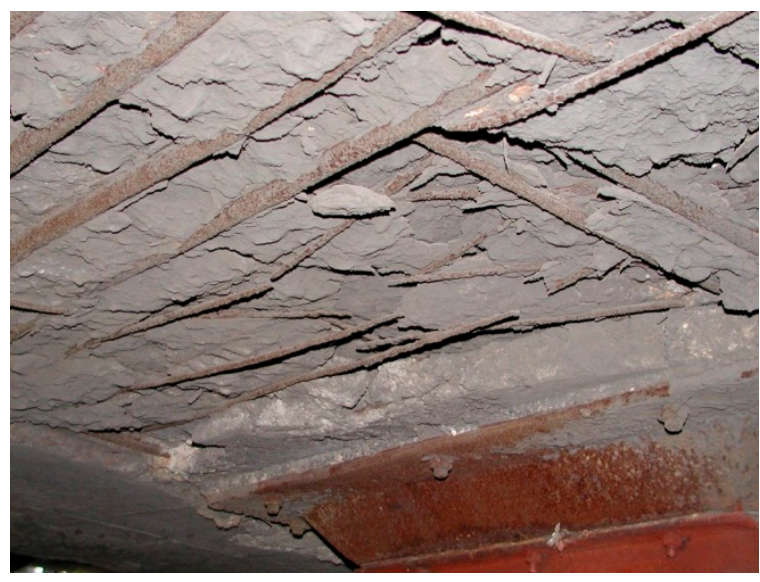

(b)

Figure 3. Examples of steel damage in one of the structure C: (a) corrosion of steel rebars with concrete damage, (b) locally interrupted reinforcement.

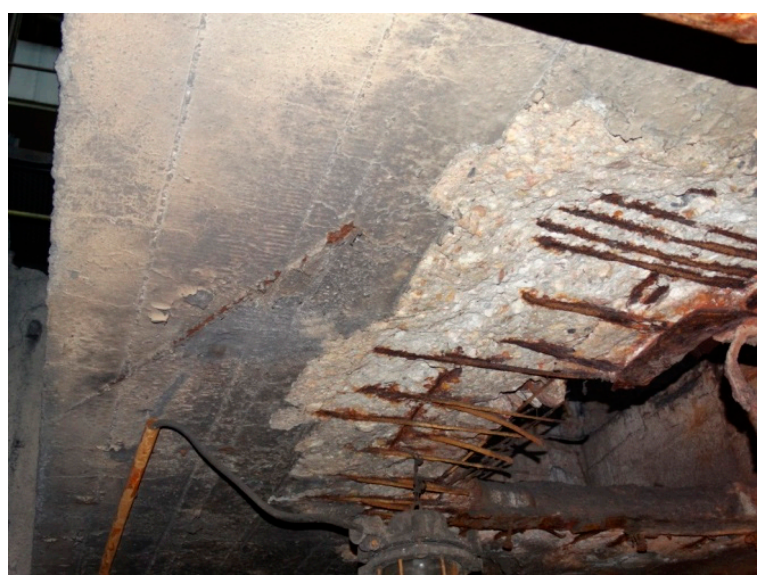

(a)

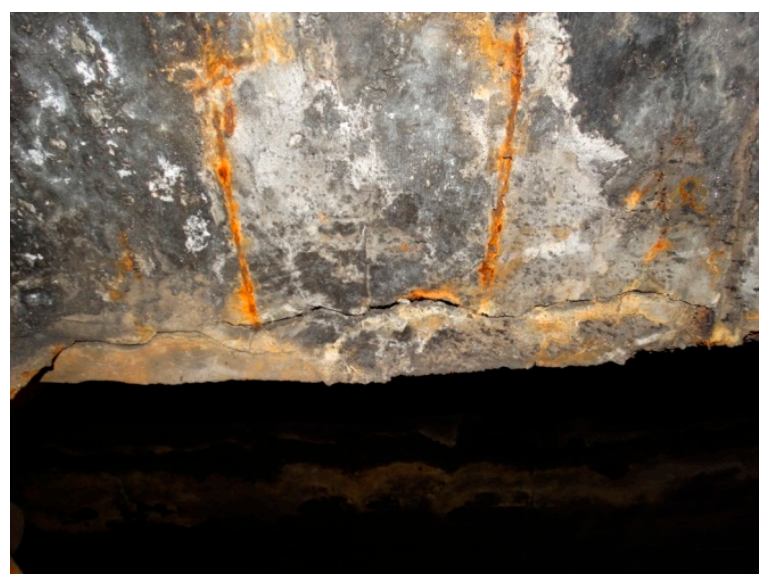

(b)

Figure 4. Examples of corrosive damage in A facility: (a) concrete and steel corrosion, (b) traces of completely corroded stirrups.

Simultaneously, the concrete in the underground parts of structures $\mathrm{C} 1$ and $\mathrm{C} 2$ retained its original structure and no reinforcement corrosion was found in the uncovered areas (the technical condition was found as satisfactory). The boilers on foundations A, C1, and C2 were supplied with Polish coal with a high content of sulfur compounds; in the case of $\mathrm{A}$, the coal was supplied directly from the mine and was damp due to contact with water containing sodium chloride. In both cases, the RC structural elements were also very damp and had contact with solid products of combustion.

The support structure of pipelines (D) showed relatively diversified results, but in all cases, the condition of structural elements was bad or very bad. In terms of $\mathrm{pH}$ value, a high threat of corrosion, especially concerning the columns was observed. The sulfate ion content was exceeded only in the columns, but the chloride ion content was drastically exceeded in all structural elements. The above was perfectly visible as enormous damage to concrete, reinforcing steel and additional steel elements (Figure 5a,b). 


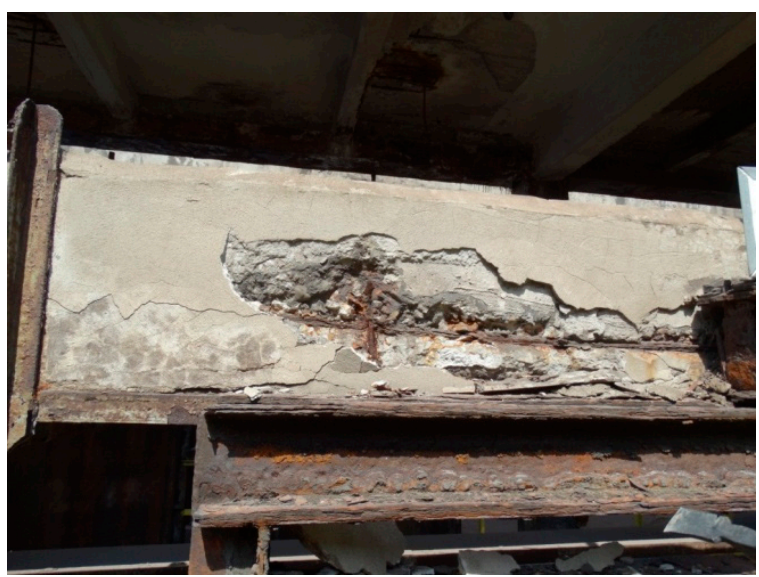

(a)

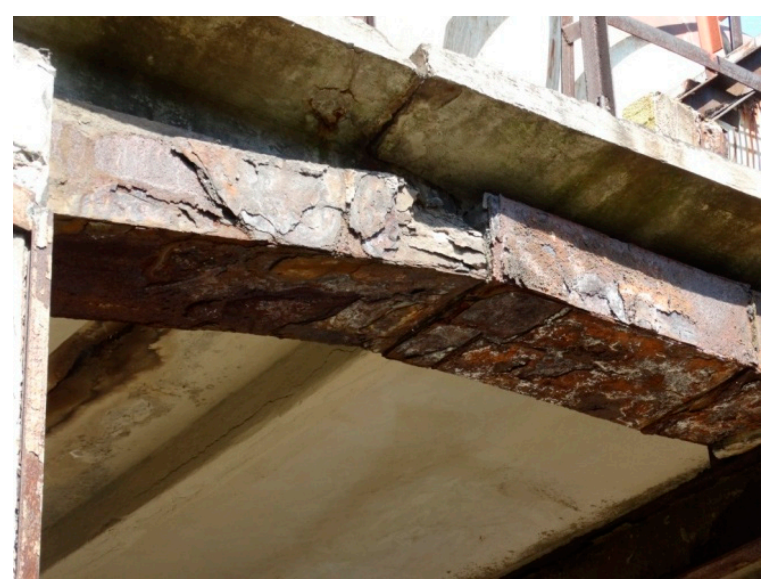

(b)

Figure 5. Damage of varying intensity: (a) damage of concrete and steel corrosion of rebars and profiles, (b) strong corrosion of steel elements used as the strengthening of concrete beams.

In many cases, the concrete burst by swelling corrosion products (Figure 6a). The structure columns were embedded in concrete and confined in an external skeleton made of steel sections approximately 20 years ago. That concrete was strongly damaged (Figure $6 \mathrm{~b}$ ), which proves that the repairs had been conducted in conditions that had not ensured their effectiveness. Similarly, the repairing layers on the beams, made using one of the PCC systems, were destroyed. It must be mentioned that the sodium chloride source was processed water in the open channels under the support structure.

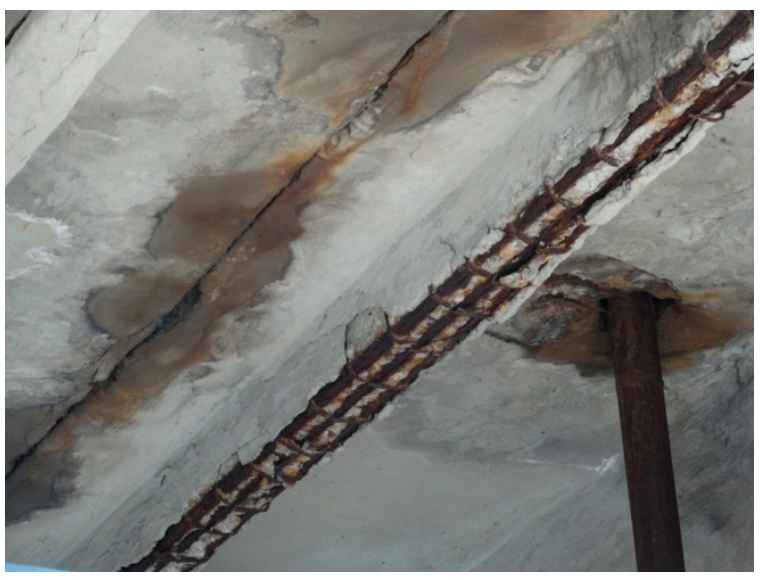

(a)

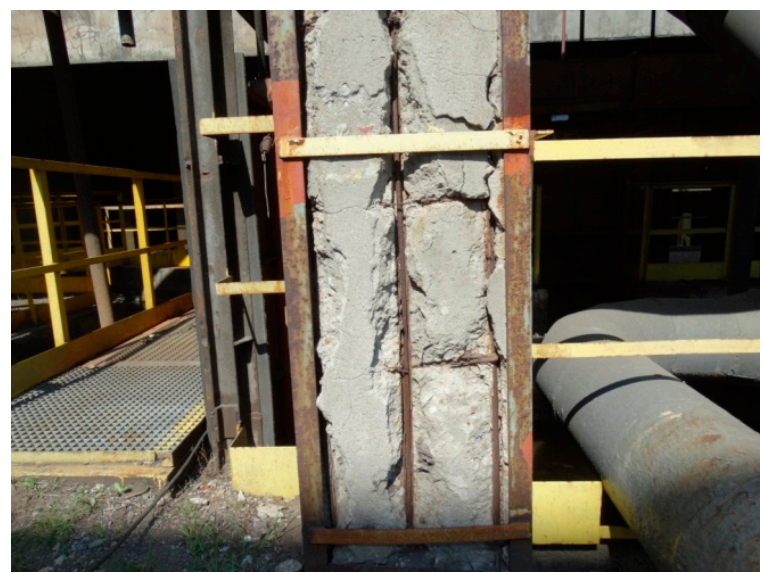

(b)

Figure 6. The very bad condition of structural elements: (a) swelling steel rebars caused damage of the concrete cover, (b) damaged steel strengthening and concrete of columns.

\subsection{Discussion on the Possibility of Repair}

The classification of damage (described above) and the decision to undertake repairs is not always strict, because it depends on a number of factors with difficult to determine weights. An external visual inspection of the structure allowing assessment of the level of damage is not a clear premise for making a decision about the ability of the structure to carry out effective and durable repairs. Despite this, in many cases, only on this basis decisions are made about the further fate (in terms of repair or dismantling) of the object. 
In the authors' opinion, the results of chemical tests served as an argument in the discussion about the final and responsible qualification of the structure for repairs or the decision to demolish it. It can be assumed, based on the authors' many years of experience, that the combination of very strong concrete contamination with harmful ions and a low $\mathrm{pH}$ was a clear premise for the demolition of the structure-especially if the expected lifetime exceeded 10 years.

In the general case, it is also necessary to take into account the possibility of liquidation of a given structure due to the continuity of technological processes in the industrial plant-in some specific cases such processes are continuous and it is impossible to stop them (e.g., operation of a blast furnace in a steel plant). In such cases, renovation may be necessary even if the condition of the structure actually precludes the sense of such activities.

In the presented case studies, the decision on further use of the facilities took into account all factors, including the results of chemical tests. In each case, the lifetime of the structures was foreseen for the next 25-30 years. All the structures from group B, despite having a weak concrete (C12/15) showed a low level of chemical contamination and relatively high $\mathrm{pH}$ value indicating a small loss of the protective capacity of concrete. This allowed the structure to be qualified for repair, and also guaranteed its effective and durable performance. The elements were repaired-since that time, they have been operated for nearly 15 years without signs of corrosion. Concerning the structures A and $\mathrm{D}$, which indicated the worst technical condition, the decision ordered the dismantling of the parts above the floor or ground level (structure D). The chemical contamination of those structures was very high, which did not provide effective repairs, especially that the area where they had to be made was very extensive (structure D). The repair of the underground parts has been approved on condition that their appropriate condition was proved, including via chemical tests-the latter was not available at the time of conducting the evaluation. The entire part above the floor level of the structures $\mathrm{C} 1$ and $\mathrm{C} 2$ were also qualified for dismantling. Despite the fact that this structure was made of relatively good concrete, with a satisfactory $\mathrm{pH}$ value (partially carbonized concrete), the intensity of damage observed as well as very high chemical contamination of concrete disqualified it from continued use. The technical condition of the underground foundation slabs was good, so it was decided to order the repair and reuse of them.

\section{Summary}

Reinforced concrete industrial structures operated for several decades often show extensive damage to concrete and reinforcing steel. Such technical condition necessitates overhauls aimed at extending the structure service life. That approach is certainly right if a given RC structure cannot be put out of operation, including the cases where it is a support structure of a device which cannot be disassembled. However, the operation time of the device itself is usually limited, so the repaired reinforced concrete structure is also going to be used for a relatively short period.

A different situation concerns a replaced device resting on an RC structure when the latter is anticipated to be used as a support element for a new device. In such a case, the RC support structure in question has to work without breakdowns for the next several decades because such is the anticipated operation time of most industrial systems. In such a situation, support structure durability becomes the basic criterion, but it is limited by the condition of that structure stemming from its previous operation period. In the case of RC, one of the most important factors is the chemical condition of the concrete, including its $\mathrm{pH}$ and contamination with chloride and sulfate ions. Those factors directly translate into the conditions of anti-corrosive protection of reinforcement and into the threat of concrete and steel corrosion. Therefore, it is justified to perform tests of concrete in this scope before deciding that an overhaul is justified.

The presented practical examples show a clear correlation between chemical pollution of concrete and the technical condition of an RC structure (both concrete and rebars). Thus, they confirm the thesis proposed herein that correct identification of selected chemical values in concrete allows one to assess both the condition of the structure and its behavior after a possible repair. It should not be clearly 
equated to a bad condition of an RC structure with the presence of high contamination with harmful chemical substances. However, it is certain that a high content of harmful ions and a decreased $\mathrm{pH}$ result in a bad technical condition and, in some cases, ineffective repairs.

The paper presents selected examples of industrial support structures, in the case of which the results of chemical tests of concrete were one of the reasons why it was decided either to perform a facility overhaul or demolish that facility and build a new one. Moreover, one of the examples shows that separating a structure fragment (a bottom slab of the foundation) from the direct action of corrosive factors results in a much better technical condition and acceptable values of chemical contamination. Consequently, the element in question was admitted for an overhaul and preserved as a part of a new support structure. The paper also demonstrates a visible correlation between the technical condition of structural elements and the results of the chemical test of concrete.

Author Contributions: Conceptualization of the paper, J.H.; presentation of the problem, J.H.; methodology of chemical test, M.K.; description and analysis of practical cases, J.H.; writing-original draft preparation, J.H. and M.K.; editing of the paper, M.K.; revision, J.H. and M.K. All authors have read and agreed to the published version of the manuscript.

Funding: This publication was performed with financial support from "Funds to maintain research potential" at the Silesian University of Technology.

Conflicts of Interest: The authors declare no conflict of interest.

\section{References}

1. Hulimka, J.; Skwarek, M. Failure of supporting structure of conveyor belt as result of impact by truck. In Awarie Budowlane. Zapobieganie, Diagnostyka, Naprawy, Rekonstrukcje; Wydawnictwo Uczelniane Zachodniopomorskiego Uniwersytetu Technicznego: Szczecin, Poland, 2015; pp. 509-516.

2. Barkey, D.P. Corrosion of steel reinforcement in concrete adjacent to surface repairs. ACI Mater. J. 2004, 101, 266-272.

3. Al-Kheetan, M.J.; Rahman, M.M.; Chamberlain, D.A. Moisture evaluation of concrete pavement treated with hydrophobic surface impregnants. Int. J. Pavement Eng. 2019, 1-9. [CrossRef]

4. Swamy, R.; Tanikawa, S. An external surface coating to protect concrete and steel from aggressive environments. Mater. Struct. 1993, 26, 465-478. [CrossRef]

5. Elnaggar, E.; Elsokkary, T.; Shohide, M.; Sabbagh, B.; Abdel-Gawwad, H. Surface protection of concrete by new protective coating. Constr. Build. Mater. 2019, 220, 245-252. [CrossRef]

6. Al-Kheetan, M.J.; Ghaffar, S.H.; Madyan, O.A.; Rahman, M.M. Development of low absorption and high-resistant sodium acetate concrete for severe environmental conditions. Constr. Build. Mater. 2020, 230, 117057. [CrossRef]

7. Bonić, Z.; Topličić-Ćurčić, G.; Davidović, N.; Savić, J. Damage of Concrete and Reinforcement of Reinforced-Concrete Foundations Caused by Environmental Effects. Procedia Eng. 2015, 117, 411-418. [CrossRef]

8. Sand, W.; Bock, E. Biodeterioration of mineral materials by microorganisms-biogenic sulfuric and nitric acid corrosion of concrete and natural stone. Geomicrobiol. J. 1991, 9, 129-138. [CrossRef]

9. Wei, S.; Sanchez, M.; Trejo, D.; Gillis, C. Microbial mediated deterioration of reinforced concrete structures. Int. Biodeterior. Biodegrad. 2010, 64, 748-754. [CrossRef]

10. O'Connell, M.; McNally, C.; Richardson, M.G. Biochemical attack on concrete in wastewater applications: A state of the art review. Cem. Concr. Compos. 2010, 32, 479-485. [CrossRef]

11. Woyciechowski, P. Model of Concrete Carbonation; Series: Scientific Works. Buildings; Warsaw University of Technology: Warsaw, Poland, 2013.

12. Kurdowski, W. Cement and Concrete Chemistry; Scientific Publisher PWN: Warsaw, Poland; Association of Cement Producers: Cracow, Poland, 2010.

13. Bellmann, F.; Erfurt, W.; Ludwig, H.-M. Field performance of concrete exposed to sulphate and low $\mathrm{pH}$ conditions from natural and industrial sources. Cem. Concr. Compos. 2012, 34, 86-93. [CrossRef]

14. Barberon, F.; Bouny, V.B.; Zanni, H.; Bresson, B.; Caillerie, J.B.; Malosse, L.; Zehong, G. Interactions between chloride and cement-paste materials. Magn. Reson. Imaging 2005, 23, 267-272. [CrossRef] [PubMed] 
15. Broomfield, J.P. Corrosion of Steel in Concrete: Understanding, Investigation and Repair; CRC Press: Boca Raton, FL, USA, 2006.

16. Smoliński, A. The economy of saline mine waters (in Polish). Min. Environ. 2006, 1, 5-15.

17. Turek, M.; Dydo, P.; Surma, A. Zero discharge utilization of saline waters from "Wesola" coal-mine. Desalination 2005, 185, 275-280. [CrossRef]

18. Hulimka, J.; Kałuża, M. A history of failure and repairs of the reinforced concrete raw coal silo. Eng. Fail. Anal. 2019, 104, 657-672. [CrossRef]

19. Glasser, F.P.; Marchand, J.; Samson, E. Durability of concrete-Degradation phenomena involving detrimental chemical reactions. Cem. Concr. Res. 2008, 38, 226-246. [CrossRef]

20. Piasta, W. Analysis of carbonate and sulphate attack on concrete structures. Eng. Fail. Anal. 2017, 79, 606-614. [CrossRef]

21. Zych, T. Durability of contemporary concrete in European Standards. Tech. Trans. Archit. 2011, 108, 317-326.

22. Hoła, J.; Bień, J.; Sadowski, Ł.; Schabowicz, K. Non-destructive and semi-destructive diagnostics of concrete structures in assessment of their durability. Bull. Pol. Acad. Sci. Tech. Sci. 2015, 63, 87-96. [CrossRef]

23. Elsener, B.; Andrade, C.; Gulikers, J.; Polder, R.; Raupach, M. Half-cell potential measurements-Potential mapping on reinforced concrete structures. Mater. Struct. 2003, 36, 461-471. [CrossRef]

24. Andrade, C.; Alonso, C. Test methods for on-site corrosion rate measurement of steel reinforcement in concrete by means of the polarization resistance method. Mater. Struct. 2004, 37, 623-643. [CrossRef]

25. Jaśniok, M.; Jaśniok, T. Measurements on Corrosion Rate of Reinforcing Steel under various Environmental Conditions, Using an Insulator to Delimit the Polarized Area. Procedia Eng. 2017, 193, 431-438. [CrossRef]

26. PN-EN 1504. Part 1 -10. Products and Systems for the Protection and Repair of Concrete Structures; Standard; Polish Committee for Standardization: Warsaw, Poland, 2006-2017.

27. Taha, N.A.; Morsy, M. Study of the behavior of corroded steel bar and convenient method of repairing. HBRC J. 2016, 12, 107-113. [CrossRef]

28. Harvey, D. Analytical Chemistry 2.0-An Open-Access Digital Textbook. Anal. Bioanal. Chem. 2011, 399, 149-152. [CrossRef] [PubMed]

29. Park, B. A statistical comparison of the gravimetric, Mohr, and Fajans methods for chloride. J. Cehmical Educ. 1958, 35, 516. [CrossRef]

30. PN-EN 14629:2008. Products and Systems for the Protection and Repair of concrete structures. Test Methods-Determination of Chloride Content in Hardened Concrete; Standard; Polish Committee for Standardization: Warsaw, Poland, 2008.

31. Climent, M.A.; de Vera, G.; Viqueira, E.; López-Atalaya, M.M. Generalization of the possibility of eliminating the filtration step in the determination of acid-soluble chloride content in cement and concrete by potentiometric titration. Cem. Concr. Res. 2004, 34, 2291-2295. [CrossRef]

32. Castellote, M.; Andrade, C. Round-Robin test on chloride analysis in concrete-Part I: Analysis of total chloride content. Mater. Struct. 2001, 34, 532-549. [CrossRef]

33. RILEM TC 178-TMC RILEM TC 178-TMC: 'Testing and modelling chloride penetration in concrete'Analysis of total chloride content in concrete. Mater. Struct. 2002, 35, 583-585. [CrossRef]

34. Vennesland, Ø.; Climent, M.A.; Andrade, C.; RILEM Technical Committee 178-TMC (Carmen Andrade). Recommendation of RILEM TC 178-TMC: Testing and modelling chloride penetration in concrete: Methods for obtaining dust samples by means of grinding concrete in order to determine the chloride concentration profile. Mater. Struct. 2013, 46, 337-344.

35. PN-EN 14630:2007. Products and Systems for the Protection and Repair of Concrete Structures. Test Methods-Determination of Carbonation Depth in Hardened Concrete by the Phenolphthalein Method; Standard; Polish Committee for Standardization: Warsaw, Poland, 2007.

36. PN-EN 206+A1:2016-12. Concrete-Specification, Performance, Production and Conformity; Standard; Polish Committee for Standardization: Warsaw, Poland, 2016.

37. Ann, K.Y.; Song, H.-W. Chloride threshold level for corrosion of steel in concrete. Corros. Sci. 2007, 49, 4113-4133. [CrossRef]

38. Angst, U.; Elsener, B.; Larsen, C.K.; Vennesland, Ø. Critical chloride content in reinforced concrete-A review. Cem. Concr. Res. 2009, 39, 1122-1138. [CrossRef]

39. Shi, X.; Xie, N.; Fortune, K.; Gong, J. Durability of steel reinforced concrete in chloride environments: An overview. Constr. Build. Mater. 2012, 30, 125-138. [CrossRef] 
40. Torres-Luque, M.; Bastidas-Arteaga, E.; Schoefs, F.; Sánchez-Silva, M.; Osma, J.F. Non-destructive methods for measuring chloride ingress into concrete: State-of-the-art and future challenges. Constr. Build. Mater. 2014, 68, 68-81. [CrossRef]

41. PN-EN 197-1:2012. Cement_Part 1. Composition, Specifications and Conformity Criteria for Common Cements; Standard; Polish Committee for Standardization: Warsaw, Poland, 2012.

42. Papadakis, V.G.; Fardis, M.N.; Vayenas, C.G. Effect of composition, environmental factors and cement-lime mortar coating on concrete carbonation. Mater. Struct. 1992, 25, 293-304. [CrossRef]

(C) 2020 by the authors. Licensee MDPI, Basel, Switzerland. This article is an open access article distributed under the terms and conditions of the Creative Commons Attribution (CC BY) license (http://creativecommons.org/licenses/by/4.0/). 